\title{
The phantasy of theory and the missing people
}

\author{
João Biehl and Sebastián Ramírez Hernandez
}

In this theoretically ambitious article, Andrés Guerrero aims to rethink the North's Master Narrative of liberal citizenship, comparing the administration of Indians in past Ecuador with the administration of illegal immigrants in Spain today "as a sort of distorted reflection."

By officially declaring the equality of all citizens in the second half of the nineteenth century, the Ecuadorian state actually dislodged and outsourced the domination of indigenous people to the sphere of everyday life and the citizenry, Guerrero argues. "The distinction between white-mestizos and indigenes was no longer a function of the Republican State, but was left to a process of identification ruled by the 'common sense' of private citizens."

Guerrero's account is built on a core paradox. In refusing to administer multiple, differentiated populations the state nonetheless crystallized those lines of differentiation and ensured their administration by other means: "beyond the State and the Law, but acting beneath its protection, we can find an unlimited effervescence of power strategies, which constitute 'molecular' movements underlying social transactions in the sphere of everyday life."

The historian uses this "imitative originality” alongside a mélange-pastiche of philosophical arguments (forcibly made to cohere but by and large only cursorily probed) to decenter or ground, as it were, liberal political rationality. While clearly invested in restoring theory to the historical enterprise, Guerrero is most eager to claim the paradigmatic quality of this "common sense citizenship" that privatizes political domination. Emanating from the South, this model is the harbinger of the neo-liberal globalized present and the vector of political theory to come.

The notion of a common sense citizenship outside of the realm of law and the direct regulation of the state is thought provoking and politically relevant. Yet the lack of discussion of the everyday mechanisms (cultural, material, economic) informing the relationship between formal citizenship and its popular counterpart limits the promise of Guerrero's claim. The mechanisms Guerrero sketches are basically unidirectional: "the people" who seem to carry the spirit of the state's abandoned policies and citizenship are envisioned almost exclusively as a means of inclusion/exclusion. From the Ecuadorian lawmakers to the European pilots and passengers in the Spanish airplane (not to mention the Indians and the North African immigrants), everyone seems to be an unwitting victim of a Master Narrative that constantly obscures its true intentions. This model begs for nuance. Citizenship can be achieved partially and piecemeal. Being outside certain communities and certain laws may well be a strategy and may offer possibilities that would remain otherwise unavailable.

Moreover, the absence of a substantial historical account of the private administration of populations is unfortunate. Guerrero purposely 
provides only glimpses of events, avoiding the "policed boundaries of history," yet it remains unclear what is gained from such an elision other than the breaking of analytical convention. If the presentation of the two cases is jarring, it is more so because of the difficulties raised by the comparison than it is due to a destabilization of the very idea of citizenship. An inventory of the common ground of both countries' political history could have borne out more nuanced accounts of the shape and charter of citizenship in modern Spain or nineteenthcentury Ecuador. If an unbalancing of the Master Narrative was the principal objective, an argument that modes of political and private citizenship were imported to Spain from the colonies could have sufficed. Yet Guerrero deliberately opts out of an account of historical processes and nuanced comparison, choosing instead a political metaphysics that thrives on the unconnected event and the paradigm outside of time.

This theoretical lure is most evident in the article's never reflected upon paradox: why the relevance of this critical political history project has to be measured by its ability to speak to the West in the present thus solidifying the West's position at the center of the intellectual universe. This is especially problematic when the question of unauthorized immigrants and the racist reactions of a country's citizens to perceived interlopers is an increasingly salient phenomenon in Ecuador itself. But this does not seem to be just the product of a theoretical stance. The article shows little engagement with Latin American historiography and social science. By ignoring the significant labor of Latin American intellectuals, Guerrero misses the possibility that other hands and voices may have sought and found distinct possibilities for understanding forms of citizenship in the continent, leveling other critiques and forging other narratives.

The model of the private administration of populations, Guerrero tells us, is coming from Ecuador. Yet what is made evident is that the model is coming from Europe, and Guerrero's reading of the Ecuadorian archives is overdetermined by the concept-work of the likes of Foucault, Bourdieu, Schultz, Habermas, Barthes, Zizek and, above all, Agamben. This is in contrast to the narrative description offered for Europe, where a dissection of specific cases and immigrant trajectories allows for a partial humanization of those excluded (even if it is to relegate them to the status of bare life).

Attending to the plurality of human becomings or ways of connecting - to oneself, to others, to public and private institutions, to the environment, to the past and to ideas of the future-are rich grounds from which to gauge the extent and impact of economic reason within governance and the civic forms and politics that accompany the simultaneous absolutization and fragility of market principles in social life. A close investigation of people's arts of existence is needed if we want to invert, as Guerrero puts it, "the usual direction in the flows of transfer and importation of 'Theory."

João Biehl is Susan Dod Brown Professor of Anthropology and Woodrow Wilson School Faculty Associate at Princeton University.

E-mail: jbiehl@princeton.edu.

Sebastián Ramírez Hernandez is a graduate student in the Department of Anthropology at Princeton University.

E-mail: srtwo@princeton.edu. 